\title{
INDIVIDUAL AND SEX DIFFERENCES BROUGHT OUT BY FASTING
}

\author{
BY HOWARD D. MARSH \\ College of the Cuty of New York
}

During the first three weeks of July, 1915, the writer and his wife undertook to share the hardships of a lengthy fast. Though not of such rigor as endured by numerous predecessors, it was yet of such reality as to produce some distinct experiences; but unfortunately the most interesting and dramatic of these were not fixable by tabulation and graphometry.

\section{General Routine}

During the first of the three weeks the food was reduced gradually from normal to near-nothing; no food was taken during the second week, but from 500 to 750 c.c. of water daily; the food conditions of the first week were exactly reversed the third week. Accurate tests of the various activities were made in the psychological laboratory of the College of the City of New York from 9 A. M. to I P. M. daily. In addition, six days of "control" tests were made at odd times but, serving badly in that capacity, have been entirely omitted from treatment here. Observations of general physical welfare and of specific physiological facts, and introspections of general mental status and particular mental tests, were recorded diurnally. Accurate analyses of the blood by a skilled physician ${ }^{1}$ and measurements of blood pressure, body temperature, pulse rate, weight changes, and lung capacity were made regularly. Graphic records of the barometric and thermometric conditions throughout the day, and verbal records of visible weather features four times a day, were taken. Our daily program provided also for customary occupations, afternoons and evenings, and was fairly uniform and controlled for the whole period.

${ }^{1}$ Dr. W. H. Boese, district clinical supervisor, Chelsea District of the New York City Health Department, etc. 


\section{The Tests}

The series of tests employed covered what may roughly be described as weight and strength, rate and accuracy, sensitivity and passivity, memory span and retentivity. Group A includes (I) weight (stripped), (2) lung capacity (wet spirometer), (3) grip, right and left hands (Narragansett dynamometer, 5 trials each hand) and (4) fatigue (hanging by the arms to the utmost endurance). .

Groups B and D include five tests, each measured by the time used and errors made: (I) Association (50 words daily from the Woodworth and Wells series, the qua ity of the associations being estimated by the number of low-grade reactions occurring); (2) naming (the 100 colors and the Ioo forms of the W. W. blanks); (3) continuous addition (roo additions daily, W. W. forms); (4) continuous subtraction (Ioo subtractions daily, W. W. forms); and (5) mental multiplication (ten 2-place problems each day).

Group C includes ( $\mathrm{I}$ ) Touch (single camel's hair, applied Io times each to top and bottom of tip of nose, positive and negative results being recorded as the hair was or was not sensed); (2) pain (Io threshold values secured from tip of nose by a Verdin algometer); (3) sight (perception of dots, irregularly arranged and ranging from 4 to 9 per card, 30 cards in all, exposed with drop screen); (4) steadiness (tracing a gradually narrowing slit, $25 \mathrm{~cm}$. long, with a metal stylus, contacts with the sides being registered by an electric buzzer, 1o trials with each hand). Taste and smell were tested for two weeks and then dropped, due to the delays and difficulties they entailed; but the results would have proven as interesting as any, had this section of our plan been completed.

Group $E$ includes ( 1 ) Immediate memory span (Io minutes allowed for memorizing the 50 words of the association list of the same day); (2) Reproduction (Io minutes allowed for recall of as many words as possible from the preceding day's memory list). The whole series of tests, it will be seen, is fairly comprehensive. 


\section{Method}

After the results were secured in terms of quantity (or time) and quality (or mistakes), they were reduced to relative ranks in each test. That is, they were distributed into ten classes giving the most normal scale. By this method the value of the steps between successive ranks varies, of course, from test to test, but in each test remains the same for both sexes, with the necessary change in starting point. It is obvious that a change amounting to one step in rank equals a change of 10 per cent. of the total range of variation displayed in each case.

An example will make this plain. For 20 days in subtraction, the times for the male in seconds were $480,438,398$, 35 I, 391, 355, 369, 308, 35 I, 330, 349, 330, 310, 31 2, 296, 288, $304,288,258,240$; and for the female 500, 498, 43I, 416, $366,357,329,330,344,310,285,300,285,296,292,298,252$, $250,255,220$. By inspection and trial it is found that the best interval to use as step is 30 seconds, and the best scale of ranks is produced by beginning for the male at 220 and for the female at 230. The tenth ranks then are '460-up' and '470-up,' respectively. Likewise the errors, ranging from none to six in the one case, and from none to nine in the other, were ranked with the step-value equaling one half.

By this method extreme cases at either end of the series are considerably 'smoothed'; but this may be an advantage rather than a disadvantage, because in a measure it counteracts the influence of uncorrected practice effect. It will be noticed that the lowest score practically is counted zero and the best, and that the rest are related to it in successively worse classes up to ten. Therefore in the last table, the results are in grades of deficiency, the larger the number the worse the ability. The value of this method of ranking, in the present investigation, lies in its provision for easy comparison of the individual with his own record rather than with an external standard; and of keeping all the results alike in form and hence in a certain sense directly correlatable in the different tests and for the different persons. Estimate of the reliability of the figures shown in terms of the prob- 
able error was not made, due to the small number of subjects involved.

TABLE I

Air aNd Blood Changes

\begin{tabular}{|c|c|c|c|c|c|c|c|c|c|c|c|c|c|}
\hline \multirow[b]{2}{*}{ Week and Sex } & \multicolumn{2}{|c|}{ Air } & \multicolumn{3}{|c|}{ Blood } & \multirow{2}{*}{ 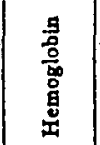 } & \multicolumn{2}{|c|}{ Common Cells } & \multicolumn{5}{|c|}{ Differential Count } \\
\hline & $\stackrel{\dot{0}}{\stackrel{d}{\leftrightarrow}}$ & $\stackrel{\dot{0}}{0}$ & 总 & 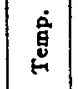 & 离 & & $\stackrel{\mathbf{z}}{\mathbf{z}}$ & $\underset{\mathscr{u}}{\tilde{\alpha}}$ & 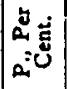 & 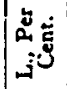 & 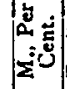 & & ن. \\
\hline Ist, $\underset{\mathrm{F}}{\mathrm{M}} \ldots$ & $\begin{array}{l}85.3 \\
85.3\end{array}$ & $\begin{array}{l}29.8 \mathrm{I} \\
29.8 \mathrm{I}\end{array}$ & $\begin{array}{l}69.3 \\
66.9\end{array}$ & $\mid \begin{array}{l}98.1 \\
97.8\end{array}$ & $\begin{array}{l}30 \\
36\end{array}$ & $\mid 90-100$ & $\begin{array}{l}7,700 \\
7,100\end{array}$ & & $\begin{array}{l}45.0 \\
56.0\end{array}$ & $\begin{array}{l}44.0 \\
36.0\end{array}$ & $\begin{array}{l}3.5 \\
0.0\end{array}$ & $\begin{array}{l}7.0 \\
4.0\end{array}$ & $\begin{array}{l}0.5 \\
1.0\end{array}$ \\
\hline 2d, $\underset{\mathrm{F}}{\mathrm{M}}$ & $\begin{array}{l}82.7 \\
82.7\end{array}$ & $\mid \begin{array}{l}29.85 \\
29.85\end{array}$ & $\begin{array}{l}71.4 \\
61.9\end{array}$ & $\mid \begin{array}{l}97.8 \\
97.5\end{array}$ & $\begin{array}{l}14 \\
18\end{array}$ & $\begin{array}{ll}u & \cdots \\
\cdots & "\end{array}$ & $\begin{array}{l}6,200 \\
6,460\end{array} \mid$ & $\begin{array}{l}6,650,000 \\
6,440,000\end{array}$ & $\begin{array}{l}67.0 \\
48.0\end{array} \mid$ & $\begin{array}{l}26.0 \\
41.0\end{array}$ & \begin{tabular}{ll|}
0 & 5.0 \\
0 & 9.0
\end{tabular} & $\begin{array}{l}2.0 \\
1.0\end{array}$ & $\begin{array}{l}0.0 \\
1.0\end{array}$ \\
\hline 3d, $\begin{array}{l}\mathrm{M} \\
\mathrm{F} .\end{array}$ & $\begin{array}{l}82.3 \\
82.3\end{array}$ & \begin{tabular}{|l|}
29.95 \\
29.95
\end{tabular} & $\begin{array}{l}75.6 \\
69.3\end{array}$ & $\mid \begin{array}{l}98.4 \\
97.7\end{array}$ & $\left|\begin{array}{l}33 \\
40\end{array}\right|$ & $\mid \begin{array}{ll}a & 6 \\
\text { a } & \text { a }\end{array}$ & $\left|\begin{array}{l}6,200 \\
7,920\end{array}\right|$ & $\begin{array}{l}5,960,000 \\
5,890, \infty 00\end{array}$ & $\left|\begin{array}{l}46.5 \\
47.8\end{array}\right|$ & $\begin{array}{l}41.0 \\
43.9\end{array}$ & \begin{tabular}{|l|l|}
0 & 3.5 \\
9 & 5.5 \\
\end{tabular} & $\begin{array}{l}7.5 \\
2.5\end{array}$ & $\begin{array}{l}1.5 \\
0.3\end{array}$ \\
\hline
\end{tabular}

P. = polynuclear; $\mathrm{L} .=$ lymphocytes; $\mathrm{M} .=$ mononuclear; $\mathrm{E} .=$ eosinophiles; B. $=$ basophiles.

\section{Results}

The results of least psychologic interest are given first and condensedly, mainly as collated in Table I. The 'air' figures were secured from a seven-day Tycos baro-thermograph, and show that the average conditions were unusually constant; hence any marked mental influences from this quarter could be ascertained only by careful correlations for each day.

The 'blood' figures are more significant, the fall in pressure for the fasting week being especially pronounced for both sexes. Temperature and pulse also fall, the only sex difference here appearing in the more marked change for the female in heart rate. It is possible that the cellular changes in the blood are most significant, though a glance suffices to show that this is not true of the white and red corpuscles. The latter fact serves to cast doubt on the popularly accepted view that the organism radically is weakened by fasting (a week or ten days)-that the guardian white cells are depleted and thus leave the body exposed to the ravages of bacterial diseases. The writer will not here try to interpret the other cellular changes tabulated, but has included them for the benefit of those who may be interested.

The results of greatest psychologic interest are sum- 
marized in Table II., classified roughly under five headings for readier handling, and described briefly as to the outcome of each group. The column marked 'descending' covers results for the first week, the first day excluded due to unavoidable irregularities; the one marked 'fasting' covers the second week and first day of the third week, the latter included because the fasting momentum was unquestionably stronger than the food influence; and the one marked 'ascending' covers the last six days of the period.

By 'fasting loss' is meant that decisive debility was produced by the food deficit; by 'practice loss,' that the anticipated gain due to practice was slowed in rate or not fully realized; by 'practice gain,' that the expectable practice gain was not impeded but appeared in normal degree; and by 'fasting gain,' that decisive ability was produced by the food absence.

Not only does the larger number mean the less ability, but the table is arranged to show first in order, both in the whole table and in its parts, those activities rendered most defective by the fasting.

The first point of interest is the high correlation between the estimated food intake and the changes in weight and strength. The results are practically uniform in trend and are in the direction one would expect.

The next thing of note is that the general trend of the next group, though indicated as "practice loss" is much less decisive than in the preceding case. This partly depends on the fact that the group is mixed, the first three tests involving an important motor element and the last two not. That is, the first three tests tend to follow the preceding group in fasting loss while the last two, more purely mental in character, more nearly simulate the succeeding groups.

In the next group, $C$, the trend is no more distinct. This again is a mixed group but does on the whole show pretty complete practice gain. There are here, as in the other groups, certain sex differences brought out. Sensitivity in the female apparently decreased in touch and sight and increased in pain in the full-fast period, but the reverse was true for the male. Otherwise sex similarity prevails. 
TABLE II

Strmanazed Results of Fasting Tests

[The larger the number the less the ability]

\begin{tabular}{|c|c|c|c|c|c|c|c|}
\hline \multirow{2}{*}{ Activities Teated } & \multicolumn{2}{|c|}{ Jescending } & \multicolumn{2}{|c|}{ Fasung } & \multicolumn{2}{|c|}{ Ascending } & \multirow{2}{*}{$\begin{array}{l}\text { Group Names and Reaults } \\
\text { (Entimated) }\end{array}$} \\
\hline & M. & F. & M. 1 & F. & M. ! & F. & \\
\hline ood Intake.... & 4.5 & 4.5 & 8.5 & 8.5 & 3.5 & 3.5 & \\
\hline \multirow[t]{2}{*}{ 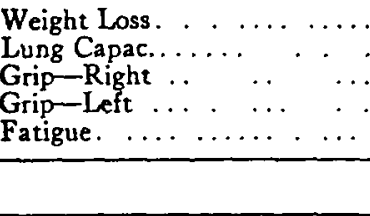 } & $\begin{array}{l}7.3 \\
5.3 \\
2.3 \\
4.0 \\
7.3\end{array}$ & $\begin{array}{l}7 \cdot 2 \\
2.8 \\
5 \cdot 7 \\
5 \cdot 7 \\
4 \cdot 3\end{array}$ & $\begin{array}{l}7.9 \\
6.8 \\
6.1 \\
7.7 \\
8.2\end{array}$ & $\begin{array}{l}7.0 \\
7.5 \\
6.9 \\
5.7 \\
8.4\end{array}$ & $\begin{array}{l}3.9 \\
2.8 \\
6.8 \\
7.5 \\
1.3\end{array}$ & $\begin{array}{l}4.0 \\
4.5 \\
5.1 \\
5.1 \\
3.7\end{array}$ & A. Vitality \\
\hline & 5.2 & 5.1 & $7 \cdot 3$ & 7.1 & 4.5 & 4.5 & Fasting loss \\
\hline \multirow[t]{2}{*}{$\begin{array}{llll}\text { Association time..... } & \\
\text { Naming time ... } & & \\
\text { Addition time..... } & \ldots & \ldots \\
\text { Subtraction time } & . & \ldots \\
\text { Multiplication time } & . & . & \\
\end{array}$} & $\begin{array}{l}4.3 \\
4.1 \\
6.3 \\
7.5 \\
8.7\end{array}$ & $\begin{array}{l}5.2 \\
6.0 \\
6.0 \\
8.7 \\
8.8\end{array}$ & $\begin{array}{l}7.3 \\
3.6 \\
6.0 \\
5.4 \\
6.3\end{array}$ & $\begin{array}{l}5.0 \\
6.7 \\
6.9 \\
5.1 \\
6.0\end{array}$ & $\begin{array}{l}4.2 \\
1.8 \\
4.5 \\
3.4 \\
2.5\end{array}$ & $\begin{array}{l}3.3 \\
3.6 \\
2.8 \\
3.3 \\
1.8\end{array}$ & B. Rapidity \\
\hline & 6.2 & 6.9 & 5.7 & 5.9 & 3.3 & 3.0 & Practice loss \\
\hline \multirow[t]{2}{*}{ 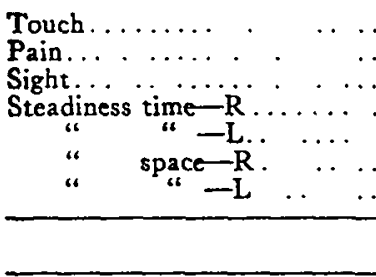 } & $\begin{array}{l}6.4 \\
4.0 \\
6.3 \\
6.5 \\
4.0 \\
6.3 \\
7.3 \\
\end{array}$ & $\begin{array}{l}5.7 \\
6.5 \\
6.6 \\
4.8 \\
4.0 \\
5.0 \\
7.3 \\
\end{array}$ & $\begin{array}{l}5.1 \\
6.0 \\
3.8 \\
2.7 \\
5.5 \\
3.6 \\
4.6 \\
\end{array}$ & $\begin{array}{l}6.2 \\
5.0 \\
4 \cdot 7 \\
4.0 \\
4.6 \\
5 \cdot 4 \\
4 \cdot 4 \\
\end{array}$ & $\begin{array}{l}4.8 \\
5.5 \\
5.5 \\
5.3 \\
5.2 \\
3.2 \\
2.7\end{array}$ & $\begin{array}{l}3.9 \\
6.8 \\
3.5 \\
5.7 \\
6.2 \\
3.5 \\
2.5\end{array}$ & C. Passivity \\
\hline & 5.8 & $5 \cdot 7$ & 4.5 & 4.9 & 4.6 & 4.6 & Practice gain \\
\hline \multirow[t]{2}{*}{$\begin{array}{l}\text { Association errors } \ldots \ldots \ldots \\
\text { Naming errors . . . } \\
\text { Addition errors... } \\
\text { Subtraction errors . } \\
\text { Multiplication errors . . }\end{array}$} & $\begin{array}{l}6.5 \\
5 \cdot 5 \\
4.0 \\
8.3 \\
5.3\end{array}$ & $\begin{array}{l}5.5 \\
6.1 \\
6.0 \\
7.8 \\
7.2\end{array}$ & $\begin{array}{l}7.0 \\
4.1 \\
2.5 \\
3.5 \\
5.1\end{array}$ & $\begin{array}{l}7.0 \\
1.8 \\
4.0 \\
3.3 \\
6.0\end{array}$ & $\begin{array}{l}4.7 \\
2.9 \\
3.5 \\
4.5 \\
5.7\end{array}$ & $\begin{array}{l}6.0 \\
3.3 \\
1.0 \\
3.8 \\
5.5\end{array}$ & D. Accuracy \\
\hline & 5.9 & 6.5 & 4.4 & $4 \cdot 4$ & 4.2 & 3.9 & Fasting gain \\
\hline \multirow[t]{2}{*}{$\begin{array}{l}\text { Memorization } \\
\text { Reproduction : }\end{array}$} & $\begin{array}{l}4.0 \\
5.0\end{array}$ & $\begin{array}{l}4.7 \\
4.7 \\
\end{array}$ & $\begin{array}{l}8.1 \\
8.5\end{array}$ & $\begin{array}{l}2.7 \\
4.2\end{array}$ & $\begin{array}{l}4.8 \\
5.0\end{array}$ & $\begin{array}{l}6.5 \\
8.1\end{array}$ & E. Memory \\
\hline & 4.5 & 4.7 & 8.3 & 3.5 & $4.9^{\prime}$ & $7 \cdot 3$ & M., loss, F., gain \\
\hline Total & 5.6 & 5.8 & 5.7 & $5 \cdot 3$ & 4.2 & 4-1 & \\
\hline
\end{tabular}

In group $D$ it must be admitted that the results are not very homogeneous in their showing or meaning. We have here that part of the given tests most distinctly mental, and while they show most betterment or fasting gain from the food abstinence, they also show most variability and hence 
unreliability. As for sex, it may be seen that there is almost perfect agreement in the several traits instead of any differences.

In truth it is only in the last group, $E$, apart from the instances already mentioned, that an undoubted difference appears, the male showing excessive deficiency and the female excessive proficiency from the given ordeal. Even here, of course, it cannot surely be said to be a 'sex' affair, since any two individuals might exhibit the same fact.

Though true that the test-results are technically most interesting, it yet is true that the introspections are informative. I shall mention some things they show of a general nature or about certain days or tests and in relation to shifts in energy, feeling, and intellection.

First, concerning the amount of correlation between the objective and subjective effects. The food was decreasing from the start and quite absent from the $7^{\text {th }}$ to the $5^{\text {th }}$, yet it may be judged that any effect from its absence would increase after the $7^{\text {th }}$ to a climax, due to new adjustments entailed on the organism; and then would decrease, due to their establishment and to the exhilaration of the approaching end. This climax does come about the IIth, showing in introspections, performances, and weight. Thus the male losses in weight from the 9 th to the 12 th are nearly nine pounds, from a total of nineteen; the female, five and a half, from a total of fourteen. In the tests, after a starting spurt of high efficiency on the 8th, there was a reactionary drop on the 9 th and thence to the 12 th, from which time improvement proceeded irregularly to the end.

Introspective records about the date of this turning-point were on the following order. Male: "Heart pounds gieatly and more or less constantly, particularly at the pit of the stomach; also beats rapidly and flutters at stair-climbing. Unable to do work afternoon or evening. Great lassitude and discomfort of general nature and in head. Throat dry but no desire for water nor liking of it. Pains in head, eyes, back, legs, especially knees and calves-lying, sitting, or standing. No nausea, but sense of instability in the stomach 
-of being easily upset. Feelings of sympathy, joy, reverence, etc., all are reduced in quality-lifeless in fact." Female: "Bath gave no pleasure. Felt like bursting out crying during mental tests and in afternoon. Greatly startled by sudden noises. Experienced hunger for the first time. At night dreamed of fried cucumbers and chopped olives being used as padding around some mechanical apparatus. To undertake anything seems a great effort and I can't speed up beyond a jog trot. My emotions have returned (on the 12th) after several days of torpor." Though physical fatigue and inertia continue after the 13 th, mental conditions begin to mend, as already suggested.

The question of 'how it feels to fast' is of main concern to most persons who have not indulged in severe dietary regimens. While the characteristic hunger sensations were experienced at meal times on several days, even occasionally accompanied by belchings, nausea and vomiting, especially in the case of the female, yet the discomfort on this account is not as gigantic as it looms in imagination. No doubt it would be truest to say that it is masked by the prevailing somatic state of ill-being or odd-being, relativity being so great a factor in all experience. The complexity and intensity of this state would appear were our introspective terms fully listed here, instead of merely sampled in the preceding paragraph.

Concerning the correlation of specific introspected feelings and actual test results, our records show very high agreement at times and equally low at others. Of roo judgments recorded by the male subject, concerning his feelings of progress and accuracy in particular tests, 60 showed positive correlation and 40 negative. For the female the matter is more ambiguous and quite undec.pherable mathematically, as this typical quotation will show: "I feel as though I am very slow in doing my tests even though they are shorter in time than usual. I have a feeling of impatience as though one part of me were having to wait for another part; and it is almost as though the impatient part were saying 'Stop trying and let me do your work; I can do it faster and better than you': and when I do stop trying, this unseen part puts 
down the answers with such great ease and speed that I marvel at its achievements." This dual-personality experience was present a number of times and the side of it which felt like 'doing things' often produced results just the opposite. In fact the correlation between the work as appraised subjectively and as measured objectively seems for the female about as negative as for the male it was positive. But the distribution of judgments in both cases would be rather close to that of 'chance.'

\section{Conclusion}

The immediate effects of the fast as shown by the tests indicate a depletion of vitality and strength commensurate with the reduction of food intake; and to some extent a slowing-down in the speed of activities, more for the motor than the mental. The sensory and passive sides of the self are not greatly affected, generally speaking, but sexually show male sensitivity for pain and perceptivity for dots increased, and for touch decreased; while for the female the reverse is true. Some improvement for both sexes is shown in mental clearness and accuracy, though not decisively; and a most pronounced effect upon memory, disadvantageous for the masculine subject and advantageous for the feminine. The feelings, unusually acute for several days and then unusually apathetic for a time, were on the whole ambiguous indices of the grades of objective performance, less so for the male than the female. Had the efforts required by the tests been more protracted and exacting in character probably the subjective-objective correlation would have been higher.

The u'timate effects of fasting, upon both health and ability, it is most desirable to know. Doctors often do not promise radical health changes without months of definite dietary changes. Ancient reports of fasts are bad scientifically through lack of proper control and measurement. Modern researches cover these points better but are bad practically from failure to shed light on an after-period. The present experiment fails similarly, due to a shift from laboratory to camping life concurrent with its completion. Instead of remaining a negligible part these remoter effects should be made the main goal of future fasting studies. 